\title{
Effects of Cooperative and Self-Learning Strategies on Physical Education and Sport Class
}

\author{
${ }^{1}$ Hadj Benkhaled, ${ }^{2}$ Ahmed Atallah, ${ }^{3}$ Hayat Touati \\ ${ }^{1}$ Laboratory Optimization of the Programs in APS \\ ${ }^{2}$ Institute of Physical Education and Sporting \\ ${ }^{3}$ University of Abedelhamid Ibn Badis, Mostaganem, Algeria
}

\begin{abstract}
This study aims to determine the effect of using some Learning Strategies for the implementing of Competency-Based Approach in the physical and sport education class. It is an attempt to identify the effects of using each Learning Strategy through the improvement of psychomotor skills relating to the chosen sport activities. The experiment protocol of three homogeneous groups (two experimental groups and one control) was used in this study, based on pre and post measurements. The test sample consisted of (72 students) of second year at high school, and it is divided in three groups, i.e. each group is composed of 24 students (12 males, 12 females). This study is based on skill tests for measuring psychomotor capacity of students, to whom the educational program has been applied. The first experimental group is exposed to Cooperative Learning Strategy; the second experimental group is subjected to SelfLearning strategy and the control group to the traditional method. Based on the obtained results, we have concluded that the usage of Cooperative Leaning Strategy is the most appropriate strategy for achieving the implementation of the CompetencyBased Approach in the physical and sport education class.
\end{abstract}

\section{Introduction}

Today's education system is based mainly on educational institutions for objective achievement related to learning process, strengthened with a high degree of competency and proficiency, and also required to meet individual learner needs for developing his skills and giving him a strong foundation on which to build full and active life dealing with different situations.

A great attention has paid to develop an academic curriculum, which is based on the contents giving as knowledge and skills from teacher to students. Holding the premise that the learner's level is weak, the learner is allowed it accept whatever teacher's feedback during a lesson without any rejection or doubt. This teaching method was based on the teaching by objectives, which was adopted to determine the objective level sequences and identifying the modes (different techniques) for its formulation, especially, the application objectives. Some recent researches have shown that teaching by objectives led to break and divide the lesson stages which resulting to several shortcomings [1]. By making our educational system to adopt a curriculum design according to new recommendations for achieving the educational objectives in line with the identified objectives for learning, it is considered that a learner is the essence element of the learning process, the implementation of the Competency Based Approach seems to be the one best method to improve the teaching and activate the learning.

The curriculum has been established in order to achieve competency with various levels during the studying at high school, beginning from learner's level, his characteristics and required objectives. The final competency has been formulated, and three terminal competencies have derived from final competency i.e. for each year of studying (the first, second and third year) would have a terminal competency, and derived from each terminal competency, three basic competencies are related to physical and sports activities which represent its basic rules [15]

The competency indicators have devised from Basic Competency, represent a function of the mark of learning and achievement according to a previous predetermined level [1]. This latter has an effect on the teacher who is considered as the essence of the educational process for accomplishing an effective teaching situation. By adopting new teaching strategies, making the learner a positive participant in the educational process [16], proportional with individual differences and growth characteristics of learner, will able to acquire the skills used in daily life within the institution or outside.

It was noted that, there is only the traditional teaching method of physical education and sports in our educational institutions, which is based on the teaching by a teacher enhanced with a model presentation without any effective contribution of 
learners in learning situations. Moreover, the ineffective teaching methods lead to fall into errors. A lot of teachers were not giving an adequate opportunity for autonomous practice and learners' initiatives, the individual differences have not taken in consideration.

It is noteworthy that the methods of learning motor skills are performed either through selflearning or by coach or teacher. The self-learning leads to increase the learning possibility of learners by best method, increasing tendencies toward course material taught by self-learning [16]. Furthermore, the self-learning (SL) process helps the learners to teach themselves using any materials or sources to achieve clear objectives without direct assistance from the teacher [14]. Studied the effect of using individual learning strategy following the programmed learning method in volley ball game, the results showed that this latter is more effective than traditional method.

Cooperative Learning method (CL) means that students contribute in small groups in order to accomplish tasks and realize projects. The tasks are structured so that each member of a group can participate in the work. The effectiveness depends on group performance rather that the performance of a student.

Cooperative Learning activities allowing the students to be active and responsible for theirs learning. Seneca advised the using of Cooperative Learning as he believes "when you teach, you learn twice". Bell and Lancaster have used the cooperative learning to groups in England. The idea of cooperative learning has extended to America, when the Lancaster's schools have been opened in New York (1806). In the last three decades of the nineteenth century, Colonel Francis Parker has defended the Cooperative Learning, followed by John Dewey who has supported the using of Cooperative Learning groups until it became part of his famous style for learning. The theoretical foundation of Cooperative Learning began in the early 1900s, was founded by Kurt Kafka who is one of the authors of the Gestalt Psychology Theory, who confirmed that the groups are active in whole units, for which the interdependence among members could vary. Kurt Lewin has developed Kafka's notions and explained that the group is the essence of mutual dependence among members [9].

Based on the theoretical foundation founded by Kurt Lewin [13]; the Cooperative and competitive attitude theories have established [5]. Later, these notions have been refined and became social interdependence Theory [8].

The usage of Cooperative Learning in physical education and sport has attracted many authors because of its positive impact on students' academic achievement and also the increasing of theirs competence. For example, [6] investigated the effect of cooperative and traditional teaching methods on the academic achievements of students and their general approach to gymnastics class. He found, as results, that the using of cooperative learning method in physical education compared to traditional teaching has a positive impact over students' academic success and practicing skills [2]. Similar results have been found in a study involving high school for determining the effects of cooperative method utilized for gymnastics unit of physical education courses on the formative achievement level of the students. They have recommended that the Cooperative learning activities can be applied in different class levels and variety of sport branches in Physical Education, however, other authors have been interested in social skills, in addition to motor skills of students [11]. They have examined the effect of a cooperative physical education program in basketball, volleyball, and traditional Greek dancing sessions on students' social skills and attitudes toward group work. The results showed that students who participated in a cooperative learning program, developed on the basis of specific social skills as learning objectives, showed enhanced social skills and attitudes toward group work shortly after the completion of the program.

The research tries to overcome the shortcomings of the implementation of the Competency Based Approach in the physical education and sport class for achievement the competencies at all levels, to meet the global trends of modern teaching by adopting accuracy teaching strategies, comprehensiveness and flexibility, and thus more efficiency in education outcomes. It provides a model for some procedural teaching strategies (Cooperative and Self-Learning) that represents one of the modern educational trends and by which the implementation of the Competency Based Approach in the physical education and sport. This research aims to identify the effect of using some teaching strategies in the implementation of the Competency Based Approach in the physical education and sport class, in order to achieve these goals some sub-goals must be achieved first which are:

1. Identification of the effect of using cooperative learning strategy in the implementation of the competency based approach in the physical education and sportive class.

2. Identification the effect of using self-learning strategy in the implementation of the competency based approach in the physical education and sportive class.

3. Identification the best teaching strategy in the implementation of the competency based approach in the physical education and sportive class. 


\section{Statement of the Problem}

From our humble experience as high school teacher as well as the numerous meetings and discussions with our distinguished department senior faculty and through the guidance that have been provided by the supervisor of this research, we have realized that the problem can be summarized in the way the Competency- Based Approach should be implemented in the physical education and sport class through the approved activities, as well as the strategies that should be implemented to achieve that.

During this research, we have tried to focus on one aspect of the first basic competency which is the skill dimension by means the capacity sense-kinetic (some skills and motor abilities) for two learning objectives. One is related to a collective activity in Handball, and the second to an individual activity in sprint for attempting to discover the strategies for educational process improvement. We held some educational strategies to experimentation and thus the answer to the main question related to discussed problem.

What is the impact of using certain teaching strategies in the implementation of the competency based approach in the physical education and sport class?

The main question leads to many sub-questions according to the teaching strategies utilized in this research:

1. What is the impact of using cooperative learning strategy in the implementation of the competency based approach in the physical education and sportive class?

2. What is the impact of using self-learning strategy in the implementation of the competency based approach in the physical education and sportive class?

3. What is the best teaching strategy in the implementation of the competency based approach in the physical education and sportive class?

\section{Research Hypotheses}

We tested the validity of these assumptions at (0.05 level):

\subsection{General hypothesis}

There are significant differences between pre and post measurement differences in favor of the post measurement when using different teaching strategies to be in favor of cooperative learning strategy in the implementation of the competency based approach in the physical education and sportive class.
Through aforementioned teaching strategies, we have attempted to verify the following subhypotheses:

1. There are significant differences between pre and post measurement in favor of post-measurement in the implementation of the Competency Based Approach in the physical education and sportive class when using cooperative learning strategy.

2. There are significant differences between pre and post measurement in favor of post-measurement in the implementation of the Competency Based Approach in the physical education and sportive class when using self-learning strategy.

3. There are statistically significant differences in the use of both teaching strategies in favor of cooperative learning strategy in the implementation of the Competency Based Approach in the physical education and sportive class when using self-learning strategy

\section{Research Methodology}

We used the experimental method by adopting the pre and post measurement design of three equal groups (two experimental and the other control). The research sample is composed of 72 students (36 males, and 36 females), distributed in three equal groups: first experimental (EG1), second experimental (EG2) and third control (CG) depending on the method of pairing or symmetry between the groups. Each group consisted of 24 students of whom (12 males, and 12 females). This sample has been selected intentionally from the original population, who are second year students of secondary education, experimental science class of Ibn Sahnoun Errashidi High School, Saida, Algeria in the 2011/2012 academic year and range in age from 16 to18 years. Their number reached 147 students, with 62 males and 85 females.

The experiment was conducted through the following stages: a pilot study has been used to test a sample of the original community during the days of September 18-19, 2011 and re-tested the same sample a week after days on September 25-26, 2011, one day for males and another for females, preMeasurements on October 2-3-4, 2011, one group per day (mornings for males and afternoons for females) and Post-Measurements on December 4-56, 2011 adopted to the same organization and conditions.

The variables of research contain the independent variables (CL and SL strategies), and also the dependent variables which are representing in the studies psychomotor capacity (passing / reception, dribbling, shoot, speed, flexibility and agility). The following instruments were used in this research for 
data collection: Cooperative Learning strategy (CL), Self-Learning strategy (SL), Teaching Curriculum (TC), Assessment.

The learning program preparation goes through different stages which should be followed, so as identify the setting objective and make the work successful. First, we analyzed the skills that led us recognize the leading logical steps and therefore respect the learning principles, error detection became easy when occurring and repairing it by adopting various pre-defined appropriate pedagogical interventions and thus developing skills performance. The learners' level and the existing individual differences have been known previously. Thus, it was easy to determine the minimum required to plan the program in SL, determining the learning groups in the cooperative learning (heterogeneous groups), and helped us in the pre/post comparisons. As far as the students' results are concerned focus is put on the effectiveness of the learning program. We relied on the gradient of the skills development by beginning with priority skills.

After, we proceeded to write the program in its final form which is evaluated by experts and specialists in order to help us in its revision. Program Application Steps have been applied by relying on the application of two session periods per week for each group, so that each educational unit took an hour and a half (90 minutes). The first and the last week were devoted to pre and post measuring respectively while sixteen sessions were planned for the learning units, each learning unit is divided into introductory part, a major part and then a final part.

\subsection{Tests}

Based on previous studies [3], [4] and [7], we have realized a series of tests designed to measure the dependent variables and putting them in the form of a special form to nominate tests. We presented it to the judges in order to have access to the determination of its validity after retrieval all tests with an agreed rate of more than $90 \%$ have been accepted. We studied the reliability test used testretest method and we have applied the tests on 16 students (08 males and 08 females), they were randomly selected from the research community and were re-tested after a week. The Pearson Correlation Coefficient between the grades obtained by students at the first time and second time has been calculated and then compared to its tabular value at the level $(\alpha \leq 0.05)$, degrees of freedom $(n-1)$ any $(8-1)$. To ensure the validity of the tests, we used the intrinsicvalidity. Considering the used tests in our research as easy, comprehensible, clear, and far from doubt and interpretation, as well as self-evaluation and the pilot study proved that the students acquisition of the performance way is very high, thus, it was easy for the work group to apply the tests, therefore, they were characterized by reliability, validity and objectivity.

\subsection{Statistical Treatment}

We dealt with significant results statistically based on: the arithmetic mean, standard deviation, Pearson Correlation Coefficient, " $\mathrm{t}$ " Student to denote the differences of associated arithmetic mean, "F" Fisher, one -way ANOVA for pre-test and posttest.

\section{Results and discussion}

Table 1 shows that the calculated reliability coefficient values and validity coefficient tests are greater than the tabular value of the estimated Pearson correlation coefficient (0.60) at the significance level (0.05) with degree of freedom (7), hence, this confirms the fact that these tests are characterized by a high degree of reliability and validity for both males and females.

\section{Table 1. The Reliability and validity tests for males and females}

\begin{tabular}{|c|c|c|c|c|c|}
\hline & \multirow[t]{2}{*}{$\mathrm{N}$} & \multicolumn{2}{|c|}{$\begin{array}{l}\text { C V coefficient of } \\
\text { Reliability }\end{array}$} & \multicolumn{2}{|c|}{$\begin{array}{c}\text { C V coefficient of } \\
\text { Validity }\end{array}$} \\
\hline & & males & females & males & females \\
\hline $\begin{array}{l}\text { Passing / } \\
\text { reception }\end{array}$ & \multirow{6}{*}{8} & 0.875 & 0.848 & 0.926 & 0.921 \\
\hline Driblling & & 0.929 & 0.994 & 0.964 & 0.997 \\
\hline Shooting & & 0.668 & 0.719 & 0.813 & 0.848 \\
\hline Speed & & 0.859 & 0.954 & 0.927 & 0.977 \\
\hline Flexibility & & 0.984 & 0.908 & 0.992 & 0.953 \\
\hline Agility & & 0.948 & 0.919 & 0.974 & 0.959 \\
\hline
\end{tabular}

Tabular value of the Pearson Correlation Coefficient at the significance level $(\alpha \leq 0.05)$ and the degree of freedom $(7)=0.60$.

Table 2 demonstrate the presence of differences with statistical significance between pre and post measurement for both groups' members, the CG exposed to the TM and EG1 in which CL strategy has used in favor of post-measurement in all studied skills for males and female, considering that the calculated value " $\mathrm{t}$ " was greater than the tabular value " $t$ " exception the shooting skill, the calculated value of " $t$ " appeared is less than the tabular value of " $t$ " of CG for males and females. Through these results, the first hypothesis was achieved because statistically significant differences are in favor of post measurement for the EG1 used the CL strategy. 
Table 2. Comparison between Pre and Post measurement results for the CG, EG1, EG2 in the studied skills tests for males and females

\begin{tabular}{|c|c|c|c|c|c|c|c|c|c|c|}
\hline & \multirow[t]{2}{*}{ Group } & \multirow[t]{2}{*}{ Gender } & \multirow[t]{2}{*}{$\mathrm{N}$} & \multicolumn{2}{|l|}{ Pre-test } & \multicolumn{2}{|c|}{ Post-test } & \multirow[t]{2}{*}{ "t" student } & \multirow[t]{2}{*}{ SIGNIFICATION } & \multirow[t]{2}{*}{ IN FAVOR } \\
\hline & & & & $\mathrm{X}$ & SD & $\mathrm{X}$ & SD & & & \\
\hline \multirow{6}{*}{$\begin{array}{l}\text { Passing / } \\
\text { reception }\end{array}$} & \multirow[t]{2}{*}{ EG1 } & males & \multirow{36}{*}{12} & 22.3 & 3.14 & 27 & 1.95 & 12.41 & Significatif & Post-test \\
\hline & & females & & 17.5 & 4.34 & 20 & 3.24 & 3.45 & Significatif & Post-test \\
\hline & \multirow[t]{2}{*}{ EG2 } & males & & 22.41 & 3.36 & 25.2 & 3.01 & 4.71 & Significatif & Post-test \\
\hline & & females & & 17.16 & 2.79 & 21.3 & 6.79 & 6.79 & Significatif & Post-test \\
\hline & \multirow{2}{*}{$\mathrm{CG}$} & males & & 22.1 & 3.12 & 23 & 3.24 & 3.45 & Significatif & Post-test \\
\hline & & females & & 17.16 & 4.34 & 20 & 3.24 & 4.81 & Significatif & Post-test \\
\hline \multirow[t]{6}{*}{ Driblling } & \multirow[t]{2}{*}{ EG1 } & males & & 5.03 & 0.78 & 4.06 & 0.29 & 5.28 & Significatif & Post-test \\
\hline & & females & & 6.65 & 0.85 & 5.03 & 0.47 & 11.7 & Significatif & Post-test \\
\hline & \multirow[t]{2}{*}{ EG2 } & males & & 5.06 & 0.77 & 4.56 & 0.54 & 4.04 & Significatif & Post-test \\
\hline & & females & & 6.74 & 0.98 & 5.55 & 0.44 & 4.95 & Significatif & Post-test \\
\hline & \multirow[t]{2}{*}{ CG } & males & & 4.96 & 0.74 & 4.83 & 0.63 & 2.43 & Significatif & Post-test \\
\hline & & females & & 6.67 & 0.93 & 6.03 & 0.73 & 7.51 & Significatif & Post-test \\
\hline \multirow[t]{6}{*}{ Shooting } & \multirow[t]{2}{*}{ EG1 } & males & & 3.33 & 2.1 & 6.66 & 1.66 & 8.04 & Significatif & Post-test \\
\hline & & females & & 2.16 & 1.19 & 6.83 & 0.83 & 14 & Significatif & Post-test \\
\hline & \multirow[t]{2}{*}{ EG2 } & males & & 3.16 & 1.58 & 4.33 & 1.77 & 4.31 & Significatif & Post-test \\
\hline & & females & & 2.25 & 1.76 & 4.5 & 1.50 & 3.80 & Significatif & Post-test \\
\hline & \multirow[t]{2}{*}{$\mathrm{CG}$} & males & & 3.25 & 1.6 & 3.58 & 1.72 & 0.93 & No Significatif & \\
\hline & & females & & 2.25 & 1.35 & 2.75 & 1.21 & 1.31 & No Significatif & \\
\hline \multirow[t]{6}{*}{ Speed } & \multirow[t]{2}{*}{ EG1 } & males & & 4.79 & 0.2 & 4.53 & 0.23 & 9.68 & Significatif & Post-test \\
\hline & & females & & 5.83 & 0.70 & 5.57 & 0.57 & 4.69 & Significatif & Post-test \\
\hline & \multirow[t]{2}{*}{ EG2 } & males & & 4.78 & 0.25 & 4.62 & 0.19 & 5.17 & Significatif & Post-test \\
\hline & & females & & 5.85 & 0.42 & 5.71 & 0.41 & 16.07 & Significatif & Post-test \\
\hline & \multirow[t]{2}{*}{$\mathrm{CG}$} & males & & 4.78 & 0.28 & 4.7 & 0.25 & 6.72 & Significatif & Post-test \\
\hline & & females & & 5.83 & 0.5 & 5.79 & 0.50 & 16.07 & Significatif & Post-test \\
\hline Flexibility & EG1 & males & & -025 & 8.79 & 0.75 & 8.44 & 4.690 & Significatif & Post-test \\
\hline & & females & & 2.08 & 6.99 & 6.33 & 6.49 & 13.91 & Significatif & Post-test \\
\hline & EG2 & males & & -0.08 & 8.44 & 0.41 & 8.39 & 3.31 & Significatif & Post-test \\
\hline & & females & & 2.25 & 5.04 & 3.58 & 4.83 & 7.09 & Significatif & Post-test \\
\hline & $\mathrm{CG}$ & males & & -0.16 & 5.52 & 0.25 & 5.81 & 2.15 & Significatif & Post-test \\
\hline & & females & & 2.16 & 7.46 & 3.33 & 7.46 & 3.92 & Significatif & Post-test \\
\hline Agility & EG1 & males & & 26.62 & 0.81 & 25.5 & 0.82 & 10.11 & Significatif & Post-test \\
\hline & & females & & 29.36 & 0.92 & 27.7 & 0.84 & 21.94 & Significatif & Post-test \\
\hline & EG2 & males & & 26.59 & 0.87 & 25.8 & 0.85 & 5.03 & Significatif & Post-test \\
\hline & & females & & 29.45 & 1.15 & 29.1 & 1.16 & 3.96 & Significatif & Post-test \\
\hline & $\mathrm{CG}$ & males & & 26.62 & 0.94 & 26.5 & 0.97 & 6.20 & Significatif & Post-test \\
\hline & & females & & 29.38 & 1.55 & 29.2 & 1.55 & 6.69 & Significatif & Post-test \\
\hline
\end{tabular}

" $t$ " tabular at the significance level $(\alpha \leq 0.05)$ and the degree of freedom $(11)=1.796$

The usage of CL strategy impacted positively on the development of the studied psycho-motor-abilities (skills and motor-abilities). According to previous similar studies [2], [6], [11] that CL strategy is one of the most modern educational trends which encourages learner's activity and make him the center of the educational process.

We find that the majority of the results confirm the effectiveness of this strategy, due to the fact that students' efforts together in heterogeneous groups led to mutual positive dependence. Every student became responsible in the learning process, weak students benefit from their advanced peers' assistance and encouragement to achieve the objective that deals with the success of both by improving self-level and ensuring the improvement of the level of his peers by cooperating with each other.

This allowed him the opportunity to be a teacher and a learner at the same time which contributed in the development of the studied skills which is in line with what is noteworthy in terms of "studies' results that have been implemented in the field of sports indicate that students who learned in cooperative groups have acquired a better motor learning "[12].As we have conducted this experiment on a sample with its age criterion which is different from all study stages, as secondary education students who are aged between 16 and 18 years are at the stage of full growth and therefore the personality, driven by their desires for a tendency to friendship and family aversion, has motivated us to adopt this kind of education as it develops the students' social and cooperative skills in which they work in groups where they work together to beat the other groups, and if their level was high they help their weak peers to learn according to the specifics of the teacher's adopted strategy. The same table demonstrate also the presence of statistical significance differences between pre and post measurement for EG2 in favor of post-measurement in all studied skills for males and females, considering that the values of the 
calculated "t" was greater than the tabular value of " $t$ ", resulted to the positive impact of the SL strategy in development of all studied skills. The above obtained results show that the research second hypothesis is correct, while the statistically significant differences between the pre and post measuring results of studied skills for both genders, indicating that the use of SL strategy impacted positively in the development of studied skills for males and females, previous similar studies confirms [16], that SL strategy positively impact to reach differs, when it is in a conventional frame random. The organized way is more appropriate than the random way without occurring a teacher or a coach, as in programmed learning.

Accordingly, SL strategy increases the learners' self-confidence, which helps the foundation of his learning proficiency, studies have shown that the learner works with a stronger motivation for his SL which makes it easier for him to choose activities related to his abilities and learning pace, making the learning process enjoyable. Whenever the learner is self-motivated to learn the skill, his learning gets more enjoying, more effective. It happens if the targeted skill is related to his needs and appropriate to his abilities and potential. The SL strategy helps the learner practices and reaching the skill without the need to be assisted. Learners self-practice personality, the research was conducted with secondary education students aging between 16-18 years, which helps them to be free of restrictions and increase their motivation to learn, increasing the effectiveness of the learning strategy.

Table 3. The values of " $F$ " calculated tabular and sum of squares within and between groups in the studied skills tests for males and females

\begin{tabular}{|c|c|c|c|c|c|c|c|}
\hline & Gender & $\begin{array}{l}\text { Source of } \\
\text { variation }\end{array}$ & Sum Sq & $\begin{array}{l}\text { Degree of } \\
\text { freedom }\end{array}$ & $\begin{array}{c}\text { Variance } \\
\text { estimation }\end{array}$ & $\mathrm{F}$ & SIGNIFICATION \\
\hline \multirow{4}{*}{$\begin{array}{l}\text { Passing / } \\
\text { reception }\end{array}$} & \multirow[t]{2}{*}{ males } & Within groups & 1931.41 & 33 & 58.52 & \multirow[b]{2}{*}{0.013} & \multirow[t]{2}{*}{ No significatif } \\
\hline & & Between groups & 1.55 & 2 & 0.77 & & \\
\hline & \multirow[t]{2}{*}{ females } & Within groups & 1334 & 33 & 40.43 & \multirow[b]{2}{*}{0.822} & \multirow[t]{2}{*}{ No significatif } \\
\hline & & Between groups & 66.500 & 2 & 33.25 & & \\
\hline \multirow[t]{4}{*}{ Driblling } & \multirow[t]{2}{*}{ males } & Within groups & 26.02 & 33 & 0.78 & \multirow[b]{2}{*}{3.53} & \multirow[t]{2}{*}{ No significatif } \\
\hline & & Between groups & 5.56 & 2 & 2.78 & & \\
\hline & \multirow[t]{2}{*}{ females } & Within groups & 49.28 & 33 & 1.49 & \multirow[b]{2}{*}{5.63} & \multirow[t]{2}{*}{ Significatif } \\
\hline & & Between groups & 16.83 & 2 & 8.41 & & \\
\hline \multirow[t]{4}{*}{ Shooting } & \multirow[t]{2}{*}{ males } & Within groups & 1.754 & 33 & 0.053 & \multirow[b]{2}{*}{1.618} & \multirow[t]{2}{*}{ No significatif } \\
\hline & & Between groups & 0.172 & 2 & 0.086 & & \\
\hline & \multirow[t]{2}{*}{ females } & Within groups & 8.28 & 33 & 0.251 & \multirow[b]{2}{*}{0.579} & \multirow[t]{2}{*}{ No significatif } \\
\hline & & Between groups & 0.290 & 2 & 0.145 & & \\
\hline \multirow[t]{4}{*}{ Speed } & \multirow[t]{2}{*}{ males } & Within groups & 258.25 & 33 & 7.826 & \multirow[b]{2}{*}{6.166} & \multirow[t]{2}{*}{ Significatif } \\
\hline & & Between groups & 96.50 & 2 & 48.25 & & \\
\hline & \multirow[t]{2}{*}{ females } & Within groups & 532.91 & 33 & 16.14 & \multirow[b]{2}{*}{5.53} & \multirow[t]{2}{*}{ Significatif } \\
\hline & & Between groups & 178.72 & 2 & 89.36 & & \\
\hline \multirow[t]{4}{*}{ Flexibility } & \multirow[t]{2}{*}{ males } & Within groups & 8.688 & 33 & 0.263 & \multirow[b]{2}{*}{6.919} & \multirow[t]{2}{*}{ Significatif } \\
\hline & & Between groups & 3.643 & 2 & 1.822 & & \\
\hline & \multirow[t]{2}{*}{ females } & Within groups & 10.612 & 33 & 0.322 & & Significatif \\
\hline & & Between groups & 6.005 & 2 & 3.002 & 9.337 & \\
\hline Agility & males & Within groups & 98.250 & 33 & 2.97 & & Significatif \\
\hline & & Between groups & 62.05 & 2 & 31.02 & 10.42 & \\
\hline & females & Within groups & 48.91 & 33 & 1.48 & & Significatif \\
\hline & & Between groups & 100.72 & 2 & 50.36 & 33.97 & \\
\hline
\end{tabular}

"F" tabular at the significance level $(\alpha \leq 0.05)$ and the degree of freedom $(12-33)=5.34$

Table 3 shows that the skills (flexibility, agility, and speed) for males, and skills (flexibility, speed) for females did not achieve any statistically significant differences as to the calculated value of " $F$ " for these skills is less than the tabular value of " $F$ ", while skills (passing/ reception, dribbling, and shooting) for males, and skills (passing/ reception, dribbling, shooting, and agility) for females showed statistically significant differences considering that the calculated value of " $F$ " in these skills is greater than the tabular value of "F". Scheffe test is used to detect the location of these differences for multiple comparisons between groups' arithmetic mean.
Table 4 demonstrates statistically significant differences between the CL strategy and TM results in the following skills: (passing/reception, dribbling, and shooting) for males and in skills (passing/reception, dribbling, shooting, and agility) for females, these differences were in favor of $\mathrm{CL}$ strategy.

There are statistically significant differences between CL strategy and SL strategy results in the skill of the shooting for males, and in the skills of agility and shooting for females in favor of $\mathrm{CL}$ strategy. It can be concluded that the CL strategy is the best in the development of passing/reception, shooting and dribbling skills for males and females, 
as well as agility skill for females. Results show that CL strategy positively impacted and is better than SL strategy and TM in psycho-motor development (skills and motor-abilities), which is passing/reception, dribbling, shooting for males and females, as well as the agility skill for females; whereas, in the rest of the studied skills such as speeding, and flexibility for males and females, and agility for males did not show any statistically significant differences, indicating that the using of any of the two learning strategies or the TM achieve convergent results. By contrast the arithmetic means show that the CL strategy has the best arithmetic mean, and this indicates that the CL strategy is better in its impact on the studied psycho-motor development (skills and motor- abilities). It could be argued that the hypothesis is achieved in terms of skills like passing/reception, dribbling, shooting for both genders and agility skill for females.
As for the other skills like (speed, flexibility) for both genders, and agility for males shows that there are no significant differences due to the lack of differences between and within groups. On the other hand, the skill of speed has evolved for the three groups, but did not show any differences between and within groups, and this is due to the speed and age characteristics and their relationship to muscle force. Though the flexibility has evolved in the three groups, it did not show any differences between and within groups, because the property requires more than two sessions a week so that the difference between and within groups. We have interpreted the lack of agility evolvement for males to age period that is characterized by increasing muscle size, bone structure for males which affects body's control ability.

Table 4. Comparison between Pre and Post measurement results at the CG, EG1, EG2 in the studied skills tests for males and females

\begin{tabular}{|c|c|c|c|c|}
\hline & \multirow[t]{2}{*}{ Method (A) } & \multirow[t]{2}{*}{ Method (B) } & \multicolumn{2}{|c|}{ The difference between the averages } \\
\hline & & & Males & Females \\
\hline \multirow[t]{6}{*}{ Passing / reception } & \multirow[t]{2}{*}{$\mathrm{CL}$} & SL & 1.750 & 3.916 \\
\hline & & TM & $4.000 *$ & $5.250 *$ \\
\hline & \multirow[t]{2}{*}{ SL } & $\mathrm{CL}$ & -1.750 & -3.916 \\
\hline & & TM & 2.250 & 1.333 \\
\hline & \multirow[t]{2}{*}{ TM } & $\mathrm{CL}$ & $-4.000 *$ & $-5.250 *$ \\
\hline & & SL & -2.250 & -1.333 \\
\hline \multirow[t]{6}{*}{ Driblling } & \multirow[t]{2}{*}{ CL } & SL & -0.504 & -0.250 \\
\hline & & TM & $-0.766 *$ & $-1.000 *$ \\
\hline & \multirow[t]{2}{*}{ SL } & $\mathrm{CL}$ & 0.504 & 0.525 \\
\hline & & TM & -0.262 & $0.475-$ \\
\hline & \multirow[t]{2}{*}{ TM } & $\mathrm{CL}$ & $0.766^{*}$ & $1.000 *$ \\
\hline & & SL & 0.262 & 0.475 \\
\hline \multirow[t]{6}{*}{ Shooting } & \multirow[t]{2}{*}{ CL } & SL & $2.333^{*}$ & $2.333^{*}$ \\
\hline & & TM & $3.083^{*}$ & $4.083^{*}$ \\
\hline & \multirow[t]{2}{*}{ SL } & $\mathrm{CL}$ & $-2.333 *$ & $-2.333 *$ \\
\hline & & TM & 0.750 & 1.750 \\
\hline & \multirow[t]{2}{*}{ TM } & $\mathrm{CL}$ & $-3.083 *$ & $-4.083^{*}$ \\
\hline & & SL & -0.750 & -1.750 \\
\hline \multirow[t]{6}{*}{ Speed } & \multirow[t]{2}{*}{$\mathrm{CL}$} & SL & -0.090 & -0.137 \\
\hline & & $\mathrm{TM}$ & -0.169 & -0.217 \\
\hline & \multirow[t]{2}{*}{ SL } & $\mathrm{CL}$ & 0.090 & 0.137 \\
\hline & & $\mathrm{TM}$ & -0.078 & -0.080 \\
\hline & \multirow[t]{2}{*}{ TM } & $\mathrm{CL}$ & 0.169 & 0.217 \\
\hline & & SL & 0.078 & 0.080 \\
\hline \multirow[t]{6}{*}{ Flexibility } & \multirow[t]{2}{*}{ CL } & SL & 0.333 & 2.750 \\
\hline & & TM & 0.500 & 3.000 \\
\hline & \multirow[t]{2}{*}{ SL } & $\mathrm{CL}$ & -0.333 & -2.750 \\
\hline & & $\mathrm{TM}$ & 0.166 & 0.250 \\
\hline & \multirow[t]{2}{*}{ TM } & $\mathrm{CL}$ & -0.500 & -3.000 \\
\hline & & SL & -0.166 & -0.250 \\
\hline \multirow[t]{6}{*}{ Agility } & \multirow[t]{2}{*}{$\mathrm{CL}$} & SL & -0.530 & $-1.395^{*}$ \\
\hline & & TM & -0.961 & $-1.500^{*}$ \\
\hline & \multirow[t]{2}{*}{ SL } & $\mathrm{CL}$ & 0.730 & $1.395 *$ \\
\hline & & $\mathrm{TM}$ & -0.430 & -0.104 \\
\hline & \multirow[t]{2}{*}{$\mathrm{TM}$} & $\mathrm{CL}$ & 0.961 & $1.500 *$ \\
\hline & & SL & 0.430 & 0.104 \\
\hline
\end{tabular}

"*" difference between arithmetic means is significant at the significance level $(\alpha \leq 0.05)$ 


\section{Conclusions}

Through the results of the study, we came up with the following conclusions:

1. The use of Cooperative Learning Strategy impacted positively in the development of the studied skills for males and females and thus in the implementation of the Competency Based Approach in the physical education and sports class.

2. The use of Self-Learning Strategy impacted positively in the development of the studied skills except the vertical jumping skill for females, and thus in the implementation of the Competency Based Approach in the physical education and sports class. 3. The use of Cooperative Learning Strategy is the best in the development of passing/reception, dribbling, shooting skills for males and females and throwing the ball to the fullest extent skill for males and agility skill for females. Consequently, the Cooperative Learning Strategy is the best in the implementation of the Competency Based Approach in the physical education and sports class. In the light of our findings and conclusions we suggest the following:

- Use of Cooperative Learning Strategy in teaching physical education and sports.

- Carry out similar studies on different educational stages with the attempt to use some learning Strategies that are compatible with Cooperative Learning whose usefulness has been proved.

- The need to focus on teachers' training on how to implement such learning strategies through ongoing training sessions.

\section{References}

[1] Atallah, A., Zitouni, A., Ben Guenab, H., (2009). Teaching physical education and sports in the light of the procedural approach goals and competencies. Algeria: Office of University Publications.

[2] B. Güneş, H. Çoknaz, (2010). The Effects of Cooperative Learning on the Achievements Of Students in Gymnastics Unit. Journal of Education 39, 207-219.

[3] Christine duret: Les fondamentaux du Hand l'initiation pour tous 300 exercices, 2 éme édition, paris édition Amphora, 1999.

[4] Bayer, C., (1993). Hand-Ball-la formation du joueur. (Troisième édition)- Paris, France: Edition Vigot

[5] Deutsch, M., (1949). A theory of cooperation and competition. Human Relations, 2, 129-152.

[6] Bayraktar, G., (2011). The Effect of Cooperative Learning on Students'approach to general Gymnastics course and Academic Achievements. Educational Research and Reviews 61, 62-71.

[7] Jand Paul Jean-Luc Pagés, (2007). Handball.Paris, France: Edition Vigot.

[8] Johnson D. W., Johnson, R., (1989). Cooperation and competition: Theory and research. Edina, MN: interaction Book Company.

[9] Johnson, D. W., \& Johnson, R., (1999). Learning together and alone: Cooperative, competitive, and individualistic learning (5th Ed.). Boston: Allyn \& Bacon.

[10] M. Domunmulan, (1977). Programmed instruction (Second Edition). (Michel Abi Fadel, Translators) Lebanon: book publishing center.

[11] Goudas, \& E. Magotsiou, M., (2009). The Effects of Cooperative Physical Education Program on Students' Social Skills. Journal of Applied Sport Psychology, 21, 356-364.

[12] Mohamed Sayeh, M., (2001). New trends in the teaching of physical education and sports (the first version). Egypt: Library and Technical Press radiation

[13] M. Reza al-Baghdadi, and Husam al-Din Hussein Abu Al-Huda, and the hopes of the entire spring, (2005). Cooperative learning (the first version). Cairo, Egypt: Arab Thought House.

[14] Mahmoud Ibrahim Wali, N., (2006). Teach volleyball skills strategy (the first version). Alexandria, Egypt: Dar to meet the minimum printing and publishing.

[15] The National Committee of the curriculum, (2006). Platform for Physical Education and Sports. Algeria: Press the National Office for Education and remote configuration

[16] Z. Ali Omar, and Ghada Abdul Jalal al-Hakim, (2008). Teaching physical education and sports ways (the first version). Cairo, Egypt: Arab Thought House. 